\title{
Samarium diiodide-mediated asymmetric reactions of 8-phenylmenthyl esters
}

\author{
Jim-Min Fang, * Ming-Yi Chen, Jiann-Shyng Shiue, Ling Lu and Jue-Liang Hsu \\ Department of Chemistry, National Taiwan University, Taipei, 106, Taiwan, Republic of China
}

Received 21 March 2000; accepted 21 April 2000

\begin{abstract}
(-)-8-Phenylmenthol was used as a chiral auxiliary to direct asymmetric reactions of its preformed carboxylates. Reduction of xanthates $\mathbf{1 a}$ and $\mathbf{1 b}$ by $\mathrm{SmI}_{2}$ likely proceeded via HMPA-bound samarium enolate intermediates. Self- and cross-pinacolic coupling reactions of 8 -phenylmenthyl $\alpha$-oxoesters were achieved in a highly stereoselective manner by treatment with $\mathrm{SmI}_{2}$ at $-78^{\circ} \mathrm{C}$. The stereochemical outcome was consistent with a chelated mode of transition states. (C) 2000 Elsevier Science Ltd. All rights reserved.
\end{abstract}

Keywords: asymmetric reactions; coupling reactions; samarium diiodide; xanthates.

Asymmetric pinacolic coupling of chiral $\alpha$-ketoamides by $\mathrm{SmI}_{2}$ has recently been reported to give 2,3-disubstituted tartaric acids derivatives in a high diastereoselectivity. ${ }^{1}$ This report prompts us to disclose our results of the related reactions using (-)-8-phenylmenthol as a useful chiral auxiliary to direct asymmetric reactions of its preformed carboxylates. ${ }^{2}$ The 8-phenylmenthyl auxiliary generally exerts better stereocontrol than the corresponding menthyl analogs in many types of reactions, such as alkylations, ${ }^{3}$ Michael reactions, ${ }^{4}$ Diels-Alder reactions, ${ }^{5}$ Wittig rearrangements ${ }^{6}$ and radical reactions. ${ }^{7}$ Application of (-)-8-phenylmenthol to asymmetric reactions of $\alpha$-oxocarboxylates has been reported, such as reduction, ${ }^{8}$ additions of organic metallic reagents, ${ }^{9}$ addition of allylstannanes or allylsilanes with the mediation of Lewis acids, ${ }^{10}$ ene reactions with the promotion of $\mathrm{SnCl}_{4},{ }^{11}$ Henry reactions, ${ }^{12}$ and photochemical [2+2] cycloadditions. ${ }^{13}$

Although $\mathrm{SmI}_{2}$ is often used as a one-electron-transfer reducing agent, ${ }^{14}$ the reaction of xanthates with $\mathrm{SmI}_{2}$ has not yet been reported. We examined the $\mathrm{SmI}_{2}$-mediated reaction of xanthates 1a and $\mathbf{1 b}$ (Scheme 1), and made a comparison with the reductions using $\mathrm{Bu}_{3} \mathrm{SnH}$. A THF solution of 1a (having $2 S$ configuration) was treated with $\mathrm{SmI}_{2}$ at $25^{\circ} \mathrm{C}$ in the presence of HMPA and $\mathrm{MeOH}$, and a mixture of epimers $\mathbf{2 a}$ and $\mathbf{2 b}$ was obtained in a ratio of 70:30. The reaction of 1b (having $2 R$ configuration) with $\mathrm{SmI}_{2}$ also gave two epimers in the same ratio. The $(2 R)$ and $(2 S)$-configurations of $\mathbf{2 a}$ and $\mathbf{2} \mathbf{b}$ were determined by correlation to the corresponding $(R)$ -

\footnotetext{
* Corresponding author. Fax: (886-2)-2363-6359; e-mail: jmfang@mail.ch.ntu.edu.tw 
and (S)-2-phenylpropanols via reductions with $\mathrm{LiAlH}_{4} \cdot{ }^{15}$ Unlike the $\mathrm{SmI}_{2}$ reduction, reductions of xanthates $\mathbf{1 a}$ and $\mathbf{1 b}$ with $\mathrm{Bu}_{3} \mathrm{SnH}$ gave $\mathbf{2 b}$ as the major product. ${ }^{7 \mathrm{c}}$ The $\mathrm{Bu}_{3} \mathrm{SnH}$ reductions in refluxing benzene yielded a 37:63 mixture of $\mathbf{2 a}$ and $\mathbf{2 b}$. The photo-initiated $(300 \mathrm{~nm}) \mathrm{Bu}_{3} \mathrm{SnH}$ reductions at $25^{\circ} \mathrm{C}$ also gave $\mathbf{2 a}$ and $\mathbf{2 b}$ in a similar ratio (29:71).

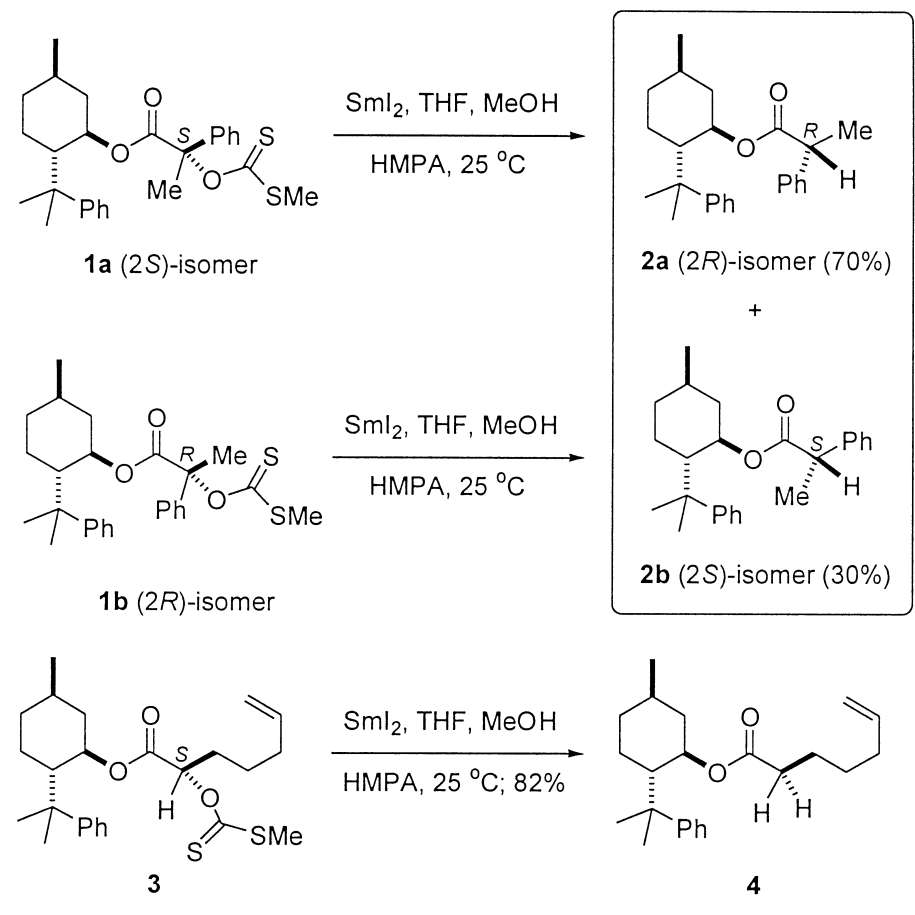

Scheme 1.

We speculated that the $\mathrm{SmI}_{2}$ reductions proceeded via enolate intermediates, whereas the $\mathrm{Bu}_{3} \mathrm{SnH}$ reductions proceeded via radical intermediates. An experiment using pentenyl-tethered xanthate 3 (Scheme 1) indicated that only reduction, giving $4(82 \%)$, but no radical cyclization occurred on treatment with $\mathrm{SmI}_{2}$. Electron transfer from $\mathrm{SmI}_{2}$ to the putative $\alpha$-carbon radical appeared to be fast to form the samarium enolates, which were likely bounded with HMPA ligands (Fig. 1). The (Z)-enolate might be disfavored by the repulsion of the phenyl substituent against the HMPA ligands. The major product 2a having the $(2 R)$-configuration could be

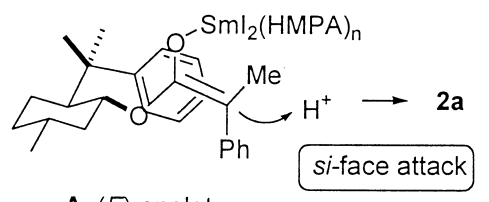

A, (E)-enolate

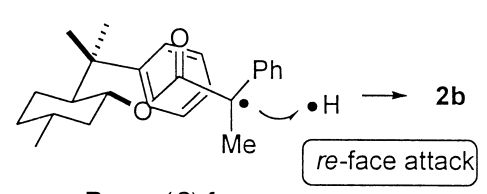

B, pro-(S) form

Figure 1. Reduction of xanthates $\mathbf{1 a}$ and $\mathbf{1 b}$ with $\mathrm{SmI}_{2}$ gave predominantly $\mathbf{2 a}$ via protonation of the $(E)$-enolate intermediate $\mathbf{A}$, of which the larger phenyl substituent was anti to the HMPA-bound samarium ion. Reduction of xanthate $\mathbf{1 a}$ and $\mathbf{1 b}$ with $\mathrm{Bu}_{3} \mathrm{SnH}$ gave predominantly $\mathbf{2} \mathbf{b}$ via the pro- $(S)$ form of the $\alpha$-carbon radical intermediate $\mathbf{B}$, of which the large phenyl substituent was anti to the 8-phenylmenthyl group 
obtained by protonation of the (E)-enolate $\mathbf{A}$ from the $s i$-face. On the other hand, the $\alpha$-carbon radical intermediate $\mathbf{B}$ with the pro- $(S)$ conformation would predominate, because it disposed the larger phenyl substituent anti to the alkoxy group of the ester. Abstraction of hydrogen atom thus occurred from the re-face of $\mathbf{B}$ to give the (2S)-epimer $\mathbf{2} \mathbf{b}$.

Pinacolic coupling reactions of 8-phenylmenthyl $\alpha$-oxoesters were achieved in a highly stereoselective manner by treatment with $\mathrm{SmI}_{2}$ at $-78^{\circ} \mathrm{C}$ (Scheme 2). Thus, the coupling reaction of (-)-8-phenylmenthyl glyoxylate (5) afforded a bis(8-phenylmenthyl) ester of $(2 S, 3 S)$-tartaric acid (8). The structure of $\mathbf{8}$ was confirmed by comparison with an authentic sample prepared from the esterification of $(2 S, 3 S)$-tartaric acid with (-)-8-phenylmenthol. ${ }^{16}$ A similar reaction of $(-)-8-$ phenylmenthyl pyruvate (6) with $\mathrm{SmI}_{2}$ gave bis(8-phenylmenthyl) (2S,3S)-2,3-dimethyltartrate (9) in $81 \%$ yield as the exclusive product. ${ }^{17}$ This asymmetric pinacolic coupling reaction constructed two stereogenic quaternary carbons. Elaboration of such a product can lead to chiral $C_{2}$-symmetric substrates useful for designing chiral catalysts. A crossed pinacolic coupling reaction of (-)-8phenylmenthyl phenylglyoxylate (7) and acetone was also effected by $\mathrm{SmI}_{2}$, giving diol 10 with the $(S)$-configuration. ${ }^{18}$

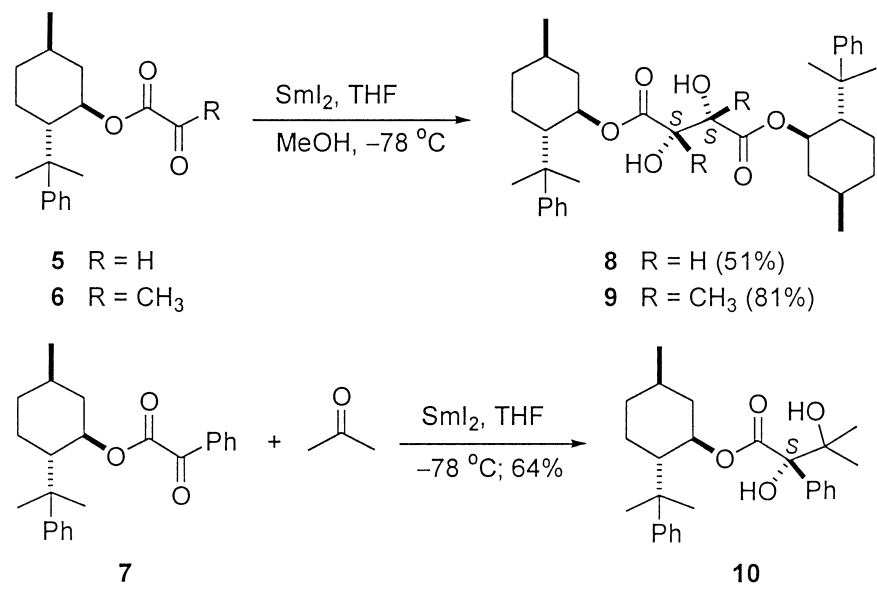

Scheme 2 .

The stereochemical outcome of pinacolic coupling reactions was consistent with a chelated mode of transition states. The tight ion pairs formed with oxygen-samarium bonds could diminish the electrostatic repulsion. The reaction might proceed via coupling of two ketyl radicals or via addition of enolate to carbonyl group. The latter pathway is illustrated in the transition state $\mathbf{C}$, which shows the $\alpha$-oxoester approaching the counter part of the samarium-chelated (Z)-enolate. Both moieties exposed their si-faces to furnish the coupling reaction in the observed stereochemistry.

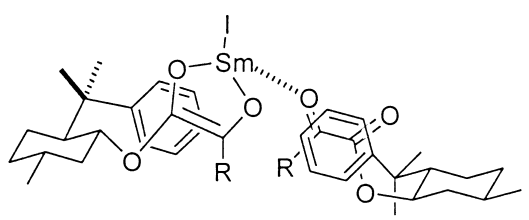

C 


\section{Acknowledgements}

We thank the National Science Council of the Republic of China for financial support.

\section{References}

1. Kim, S. M.; Byun, I. S.; Kim, Y. H. Angew. Chem., Int. Ed. 2000, 39, 728. The first report of $\mathrm{SmI}_{2}$ mediated pinacolic coupling reactions: Namy, J. L.; Souppe, J.; Kagan, H. B. Tetrahedron Lett. 1983, 24, 765.

2. Part of this study has been reported in the 'First Belgo-Taiwanese Organic Chemistry Workshop', Louvain la Neuve, Belgium, Nov. 10-13, 1999.

3. Ihara, M.; Takahashi, M.; Niitsuma, H.; Taniguchi, N.; Yasui, K.; Fukumoto, K. J. Org. Chem. 1989, 54, 5413.

4. (a) Oppolzer, W.; Loher, H. J. Helv. Chim. Acta 1981, 64, 2808. (b) Corey, E. J.; Peterson, R. T. Tetrahedron Lett. 1985, 26, 5025 .

5. (a) Corey, E. J.; Ensley, H. E. J. Am. Chem. Soc. 1975, 97, 6908. (b) Oppolzer, W.; Kurth, M.; Reichlin, D.; Chapuis, C.; Mohnhaupt, M.; Moffatt, F. Helv. Chim. Acta 1981, 64, 2802.

6. Takahashi, O.; Mikami, K.; Nakai, T. Chem. Lett. 1987, 69.

7. (a) Vaßen, R.; Runsink, J.; Scharf, H.-D. Chem. Ber. 1986, 119, 3492. (b) Hamon, D. P. G.; Razzino, P.; MassyWestropp, R. A. Chem. Commun. 1991, 332. (c) Chen, M.-Y.; Fang, J.-M.; Tsai, Y.-M.; Yeh, R.-L. Chem. Commun. 1991, 1604.

8. Whitesell, J. K.; Deyo, D.; Bhattacharya, A. Chem. Commun. 1983, 802.

9. (a) Whitesell, J. K.; Bhattacharya, A.; Henke, K. Chem. Commun. 1982, 988. (b) Hubscher, J.; Barner, R. Helv. Chim. Acta 1990, 73, 1068. (c) Chen, M.-Y.; Fang, J.-M. J. Org. Chem. 1992, 57, 2937.

10. (a) Yamamoto, Y.; Maruyama, K.; Yatagai, H.; Ishihara, Y.; Maeda, N. Tetrahedron 1984, 40, 2239. (b) Grossen, P.; Herold, P.; Mohr, P.; Tamm, C. Helv. Chim. Acta 1984, 67, 1625. (c) Chen, M.-Y.; Fang, J.-M. J. Chem. Soc., Perkin Trans. 1 1993, 1737.

11. Whitesell, J. K.; Bhattacharya, A.; Aguilar, D. A.; Henke, K. Chem. Commun. 1982, 989.

12. Solladie-Cavallo, A.; Khiar, N. Tetrahedron Lett. 1988, 29, 2189.

13. Weuthen, M.; Scharf, H.-D.; Runsink, J.; Vaßen, R. Chem. Ber. 1988, 121, 971.

14. $\mathrm{SmI}_{2}$ can effect Barbier-type reaction and the reduction of $\alpha$-heterosubstituted carbonyl compounds. Examples for $\mathrm{SmI}_{2}$-mediated reduction of $\alpha$-hydroxy and $\alpha$-alkoxy carbonyl compounds: (a) White, J. D.; Somers, T. C. J. Am. Chem. Soc. 1987, 109, 4424. (b) Holten, R. A.; Williams, A. D. J. Org. Chem. 1988, 53, 5981. (c) Pratt, D. V.; Hopkins, P. B. Tetrahedron Lett. 1987, 28, 3065. (d) Enholm, G. J.; Jiang, S. Tetrahedron Lett. 1992, 33, 313. (e) Molander, G. A.; Hahn, G. J. Org. Chem. 1986, 51, 2596. (f) Otsubo, K.; Inanaga, J.; Yamaguchi, M. Tetrahedron Lett. 1987, 28, 4437.

15. Eliel, E. L.; Freeman, J. P. J. Am. Chem. Soc. 1952, 74, 923. (b) Cohen, J. B.; Marshall, J.; Woodman, H. E. J. Chem. Soc. 1915, 107, 887.

16. The acid-catalyzed esterifications of $(2 S, 3 S)$ - and $(2 R, 3 R)$-tartaric acids with $(-)$-8-phenylmenthol were conducted in refluxing benzene with azeotropic removal of water to give, respectively, the authentic samples of 8 and its $(2 R, 3 R)$-diastereomer.

17. All the new compounds are characterized by spectral methods (IR, MS, HRMS, ${ }^{1} \mathrm{H}$ and ${ }^{13} \mathrm{C} \mathrm{NMR}$ ). Compound 9: $[\alpha]_{\mathrm{D}}^{26}-2.5\left(\mathrm{CHCl}_{3}, c=1.2\right)$. Compound 10: $[\alpha]_{\mathrm{D}}^{26}+7.0\left(\mathrm{CHCl}_{3}, c=1.0\right)$.

18. The crossed pinacolic coupling reaction of (-)-8-phenylmenthyl pyruvate and acetone was also carried out by treatment with acidic $\mathrm{TiCl}_{3}$ aqueous solution. Chen, M.-Y., Ph.D. Thesis, National Taiwan University, 1991. 